\title{
Senior Design at Cal Poly: A Recipe for Success
}

\author{
Dr. Rob McDonald ${ }^{1}$, Dr. Jordi Puig-Suari ${ }^{2}$, Mr. Dave Esposto ${ }^{3}$, and Mr. Bruce Wright ${ }^{4}$ \\ Aerospace Engineering, California Polytechnic State University, San Luis Obispo, CA, 93407
}

\begin{abstract}
The Aerospace Engineering Department at Cal Poly has, over the years, evolved a unique recipe for Senior Design. This recipe has been applied to the capstone Aircraft and Spacecraft design courses and will soon be extended to an Unmanned Aerial Vehicle design course. This recipe consists primarily of a year long design sequence with a great deal of participation from the region's aerospace industry. The Cal Poly recipe has proven to be both flexible and effective. The authors believe it could be adapted and applied in a similar manner at other institutions with a similar degree of success.
\end{abstract}

\section{Introduction}

$\mathrm{T}$ HE Aerospace Engineering senior design courses at Cal Poly, San Luis Obispo, are truly unique in their structure, approach, culture, and in the results they produce. Over the years, a series of design instructors have developed an unconventional 'recipe' for Senior Design centered around a large degree of industrial cooperation.

The design program at Cal Poly is widely recognized as being the foundation of the department, and the reason for the outstanding reputation we enjoy. Cal Poly Aerospace Engineering over the years has developed and evolved an extremely successful recipe for teaching Senior Design. This model has been applied to Aircraft and Spacecraft Design, and next year, it will be extended to UAV Design.

\section{Recipe for Senior Design}

Over the years, the Aircraft Design course at Cal Poly has evolved a unique and successful structure giving the students a 'Learn by Doing' capstone experience designing an aircraft. The course involves an intense student workload, an open-ended curriculum, and a great degree of industrial participation. In 1997, a Spacecraft Design course was created to compliment the Aircraft course. Observing and inspired by the success of the Aircraft course, the faculty created the Spacecraft course using much the same model. Although these courses have significant difference in approach and implementation, they share common ingredients combined in a similar manner - a recipe for senior design.

Table 1. The 'recipe' for Cal Poly Aerospace Senior Design.

\author{
$\underline{\text { Ingredients }}$ \\ Highly motivated students \\ All year lecture \& lab format \\ Reception \& Symposium \\ Tenure track faculty \\ Instructor retired from industry
}

\author{
Processes \\ On-site critical reviews \\ Industrial tours \\ Industry sponsorship \\ Independent learning
}

The cornerstone of the Cal Poly design recipe is close cooperation with industry. The primary components of this cooperation are the trips each Senior Design class makes each year. Each trip has two primary phases. First, an up-close tour of a working industrial facility - the students are able to observe manufacturing plants, aerodynamic, structural, propulsion, and acoustic test facilities, flight test, operations, etc. Second, the students participate in a critical review session performed by a panel of technical experts supplied by the company. This 'wire-brushing' is a

\footnotetext{
${ }^{1}$ Lockheed Martin Endowed Professor, Aerospace Engineering, AIAA Member.

${ }^{2}$ Professor, Aerospace Engineering, AIAA Member.

${ }^{3}$ Instructor, Aerospace Engineering. Chief Engineer, Boeing Satellites, Retired.

${ }^{4}$ Instructor, Aerospace Engineering. Program Manager, Lockheed Martin Skunk Works, Retired. 
unique opportunity which prepares the students for work and gives the company a unique look at Cal Poly's graduates.

The joint Aircraft/Spacecraft reception and poster session provides a great opportunity for the visitors to get to know the students one-on-one in an unstructured setting. Many of the reviewers in attendance have participated in one of the year's previous reviews; they are always interested to see how the student's work has progressed. The symposium follows the day after the reception. This symposium includes an additional critical review, giving an opportunity for members of academia, industry, and government to review the students. While the reception and poster session combine the Aircraft and Spacecraft students and reviewers into one event, the Aircraft and Spacecraft symposia are held in separate facilities. Reviewers are welcome to wander from one to the other, but most remain in the session they are most familiar with. The involvement of Industry doesn't stop there. The Senior Design program is almost entirely sponsored by Industry. In addition, the current instructor teams in both aircraft and spacecraft design courses includes a tenure-track faculty as well as retired industry professional. We find that this combination of skills and experiences provides an ideal environment to fosrter student learning in a hands-on design course.

While this model naturally evolved in Southern California, there is no reason it could not be applied by schools in other parts of the country. Concentrations of related Aerospace companies lead to obvious candidates for a program such as this including General Aviation Design in Kansas, Gas Turbine Design in the Ohio/Indiana area, and Helicopter Design in the Northeast. Even if such a concentration does not exist, application of this model to one or two trips a year would be possible in most parts of the country. The design faculty at Cal Poly would be happy to aid any university attempting to develop such a relationship for their design program.

\section{Aircraft Design Course}

The aircraft design course at Cal Poly established the first example of what can now be viewed as a 'recipe'; this evolution through the 2007 academic year has been eloquently documented by former instructors in Refs. 1-9. Of course, this course has continued to improve, with many of the most recent changes detailed in Section V of this paper.

The 2007/2008 Design class was a great success. The class traveled to Boeing Phantom Works in Huntington Beach and Long Beach, Lockheed Martin Skunk Works in Palmdale, Northrop Grumman Integrated Systems in E1 Segundo, and to the Air Force Flight Test Center at Edwards Air Force Base. For the first time in many years, the design class also traveled to Boeing Commercial Aircraft (BCA) in Seattle Washington for a three-day, four-night trip. Photos from the April trip to the Air Force Flight Test Center and the May trip to Boeing Commercial Aircraft are included as Figure 1 andFigure 2, respectively.

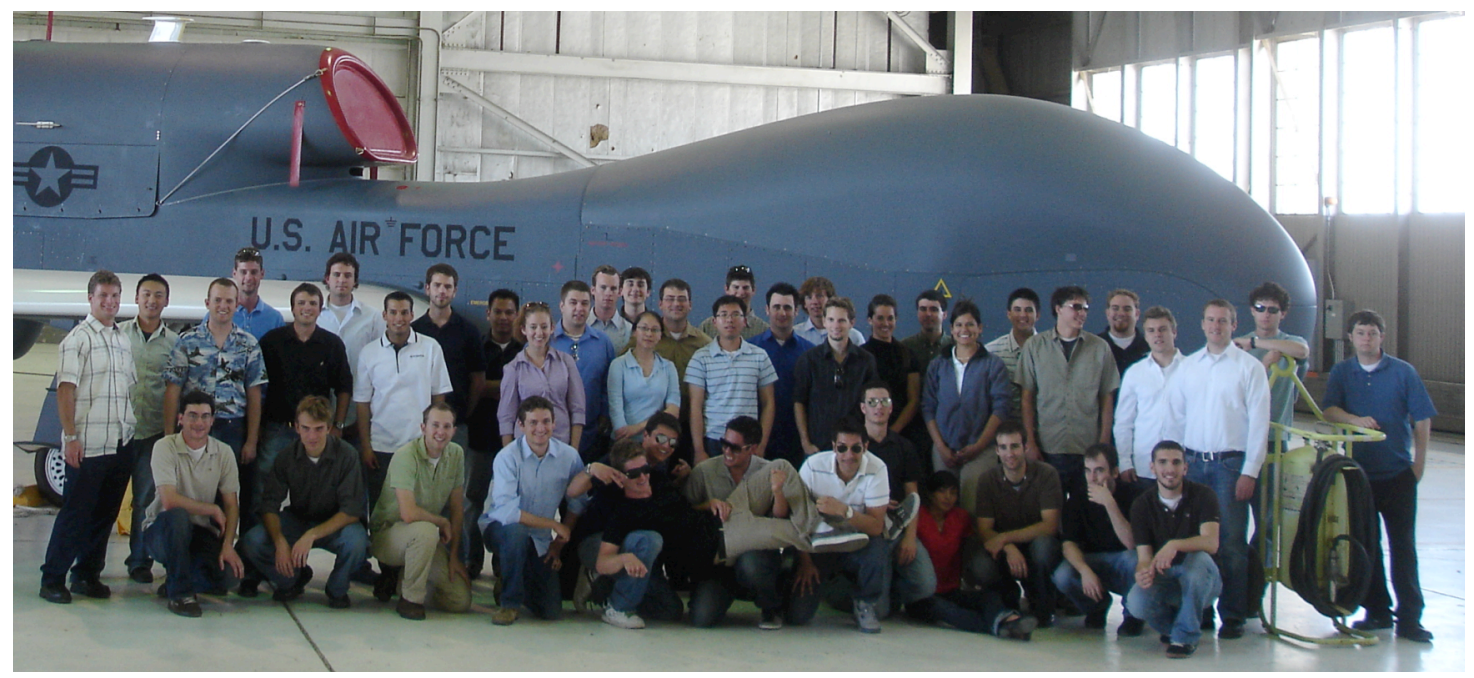

Figure 1. Cal Poly Aircraft Design at the Air Force Flight Test Center. 


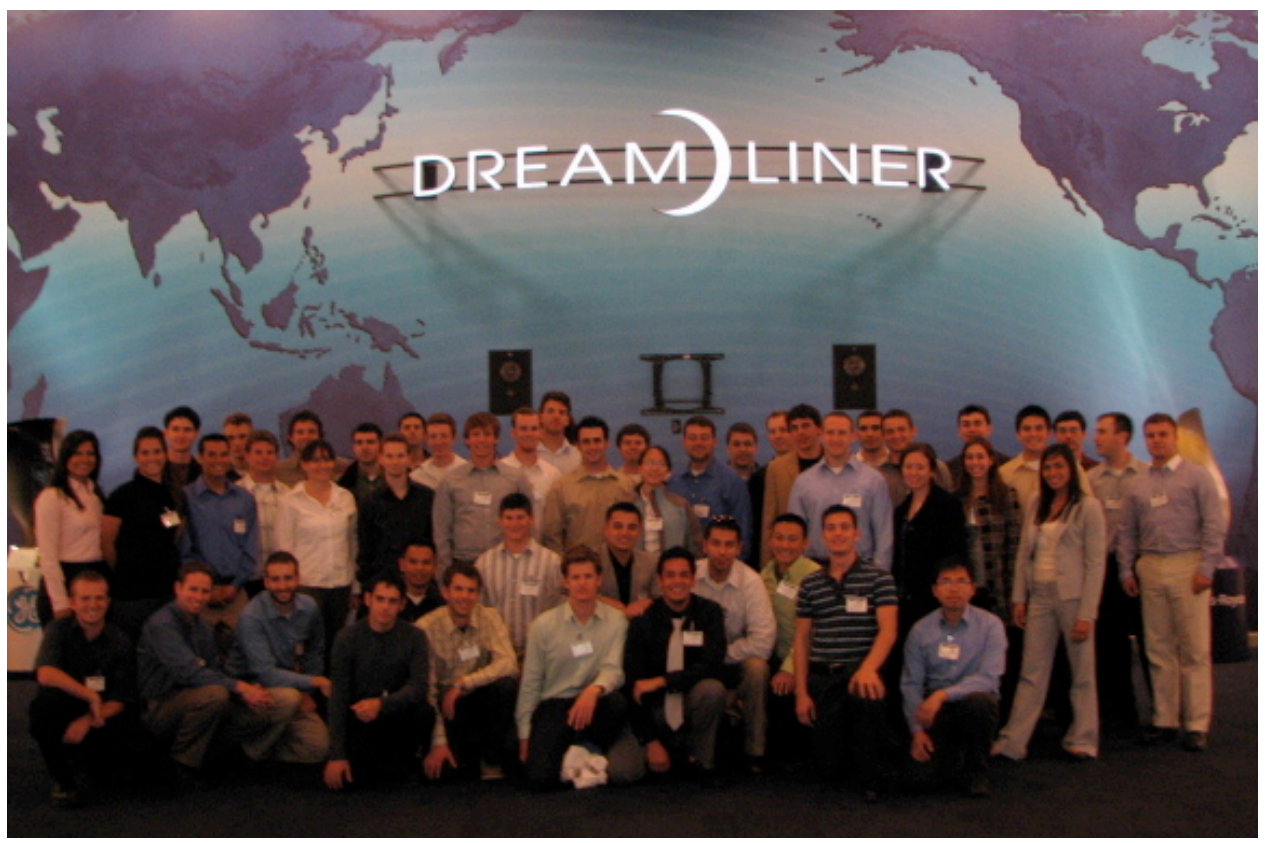

Figure 2. Cal Poly Aircraft Design at Boeing Commercial Aircraft.

These trips are depicted in Figure 3, a map of the western United States with markers locating each destination in relation to San Luis Obispo, CA. A $200 \mathrm{mi}$ radius circle is included for reference. The single-day trips start by meeting a bus on campus at $3 \mathrm{am}$; the review and tour makes for a long day, we usually don't arrive home until after $10 \mathrm{pm}$. The trip to Edwards has been a two day experience - the tour and review each took a full day. Students carpool to and from the area with an overnight stay. The trip to BCA started with a bus ride to San Jose (within the 200mi circle) and a flight to Seattle. The class spent three days/four nights in Seattle, the tour and review each took a full day.

At the conclusion of the academic year, the Aircraft and Spacecraft Design students jointly hosted an additional review. The 2008 Reception and Symposium were attended by more than sixty

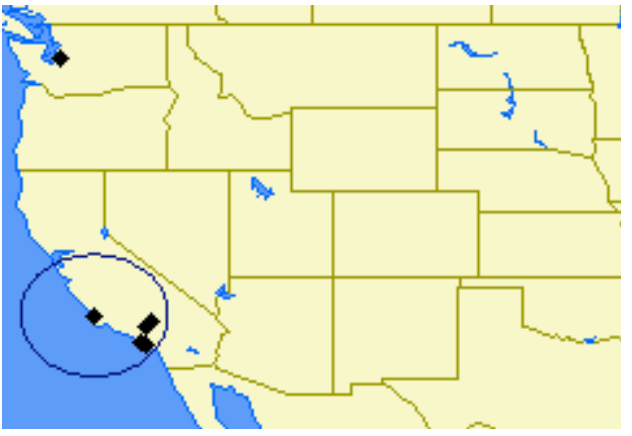

Figure 3. Trips taken by the ' $07 /$ '08 Aircraft Design class. representatives of industry, academia, government, and alumni from across the country.

Seven Aircraft Design teams made up of forty students entered the international AIAA Undergraduate Team Aircraft Design competition. Cal Poly continued its tradition of excellence in this competition; our teams came in $1^{\text {st }}, 2^{\text {nd }}$, and $3^{\text {rd }}$ place.

\section{Spacecraft (Satellite) Design Course}

Although this 'recipe' was developed by the Aircraft Design faculty, in 1997 Dr. Jordi Puig-Suari was hired to improve the Astronautics side of the department, hoping to one day equal the strength of the Aeronautics side. One of the major ways this improvement has been pursued is by creating a Spacecraft Design track using the same 'recipe' of industrial participation as that used for Aircraft Design.

The spacecraft design activity at Cal Poly started as a one-quarter elective course but in the 1997-8 academic year a full year long capstone course was offered for the first time. That first year the class was taught by the same design staff teaching the aircraft design course and the students designed of a low-cost orbital launch vehicle. The following academic year, new staff was hired to improve the spacecraft design sequence and local industry advisors were involved in the development of the RFP. This signaled the beginning of a long-term effort to develop a spacecraft design course that would match the levels of excellence reached by Cal Poly's aircraft design sequence. This effort was largely a response to the demands from industry representatives from the companies hiring Cal Poly's aerospace engineering students. 
The majority of the space industry in California is involved in the development of satellites. These are the primary employers of Cal Poly's students in the astronautics concentration. In order to address the needs of industry the RFP for the class moved from a launch vehicle to a satellite. In addition, due to the fact that the AIAA Spacecraft Design Competition RFP is not always spacecraft based, the class RFP was developed internally with the help of industry advisors. This industry supported RFP development process illuminated several key educational topics that should be included in the spacecraft design course. These topics were based on current industry needs as well as perceived weaknesses in new hires and included:

- Exposure to the early stages of the design process when requirement are being developed from customer needs.

- Introduction to systems engineering topics such as: Requirements flow-down and analysis, trade studies, system architecture, systems and subsystems integration, integration and testing processes, and cost analysis.

- Exposure to all subsystems in a spacecraft including those traditionally not included in aerospace engineering curricula such as communications, power, space science payloads, operations and ground support systems.

- Exposure to highly complex systems and systems of systems.

- Experience working in large teams (multidisciplinary teams are preferred)

- Detailed analysis of some of the subsystems to confirm the results of the preliminary design.

- Utilization of industry standard high-end computer tools such as CAD and FEA packages.

These topics became a guide for the future development of the class and still represent some of our metrics for success. In addition, they represent clear guidelines in the development of the RFP for the class since certain topics cannot include all of the topics above.

During the first few years the class was relatively small (10 to 15 students) and the RFP's involved the design of a single earth orbiting spacecraft with the students organized in a single team. As the years passed the quality of the designs improved and the RFP's became more complex including several interplanetary missions. The quality of the equipment and resources available to the students improved as well with the acquisition of computers and software tools. These improvements were largely made possible thanks to industry support for the course in a clear parallel with the aircraft design class. Again following a tradition initiated by the aircraft design class, industry trips became a critical part of the course. Field trips included TRW (now Northrop Grumman Space Technology), Hughes Space and Communications (now Boeing Satellite development Center), Lockheed Martin Space Systems, Jet

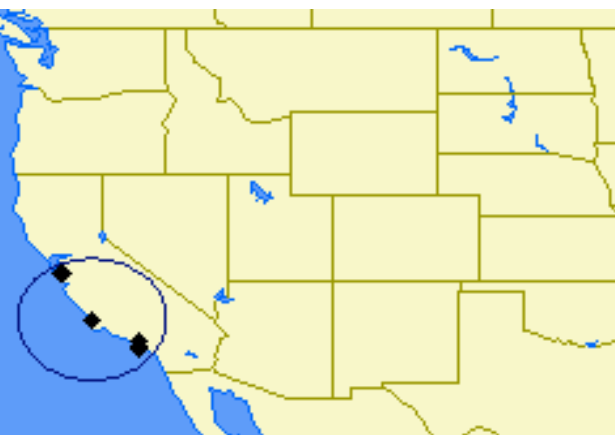

Figure 4. Trips typically taken by the Spacecraft Design class. Propulsion Laboratory, and Space Systems Loral; these trips are depicted on a map of the western United States in Figure 4.

After a few years, the class has grown in size as a result of the increased enrollment in the Aerospace Engineering program. This growth in student population (with classes of over 30 students) required some changes to the RFP. However, these changes had to be consistent with the educational objectives. As a result the RFP's were modified to involve missions that required multi-spacecraft systems. With several vehicles to design, the problems became complex enough to accommodate a large group of students while allowing the students to be organized in a single large team. This new RFP model provided a great platform to expose the students to complex systems and systems of systems problems. In addition the experience provided by such a large team environment was extremely valuable to employers.

After several multi-spacecraft RFP's it was determined that the initial phases of the design were not appropriate for such large teams of students. As a result a final change to class structure was introduced last year. During the first quarter the class is structured in small student teams (7-10 people). Each team develops an overall mission architecture to satisfy the class RFP. A winning architecture is selected and the students merge into a single team for the remainder of the design. 


\section{Recent Evolution and Changes}

Despite its success, the Senior Design program at Cal Poly has not gone without criticism. In recent years, our industrial partners have requested a change in emphasis of the education given our students. In general, industry has pushed for a general increase in the technical quality of the work and for the inclusion of emerging topics of interest. These requested topics include parametric solid modeling, Systems Engineering, parametric design techniques, and Multidisciplinary Design Optimization (MDO).

The faculty responded to these requests proactively. In 2006, Dr. Rob McDonald was hired to involve a permanent tenure-track faculty member in Aircraft Design. He was tasked with strengthening and modernizing the design program, enhancing its integration with the rest of the department, and maintaining the history of excellence. In the Spring of 2007, a graduate elective course in MDO was introduced for motivated seniors and Masters students. Its impact was noticed immediately; students applied the techniques they learned in MDO to their design projects without any further encouragement. In 2008, this course was moved to the Winter quarter in part to further encourage this knowledge transfer.

In the Fall of 2007, the design curriculum was rearranged slightly to create a lecture on Systems Engineering and Design topics. Importantly, this lecture is a joint class - students from both Aircraft and Spacecraft are jointly enrolled. Most of the techniques used to design complex systems are common. This fact is reinforced to the students through the joint lecture.

In the Fall of 2007, the Aircraft and Spacecraft Design labs moved into a brand new building on campus. This gave the funds and opportunity to re-think what a design studio should be. The labs have been furnished with dynamic furniture which can be easily re-arranged to suit the student's needs. Because so many students have their own laptop - a trend sure to continue - the lab has been outfitted with a smaller number of very high end computers. Innovative technologies such as SmartBoards and 3D pointing devices are readily available.

The Aerospace Engineering department at Cal Poly has enjoyed strong growth for the past few years (Table 2). In 2002, there were 49 students enrolled in Aircraft and Spacecraft design; this has increased to 77 students in the Fall of 2008. This growth has been accommodated without any dramatic change to the approach to the courses.

Table 2. Cal Poly Aerospace Engineering recent enrollment data.

\begin{tabular}{|c|c|c|c|c|c|c|c|c|c|c|c|c|c|}
\hline & 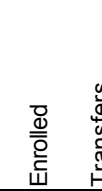 & 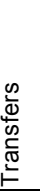 & $\begin{array}{l}\frac{0}{0} \\
\frac{\pi}{0} \\
\frac{5}{0} \\
\frac{0}{5} \\
5\end{array}$ & $\begin{array}{l}\frac{0}{\frac{\pi}{\pi}} \\
\frac{2}{0} \\
\frac{\pi}{0}\end{array}$ & 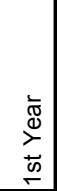 & 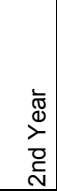 & 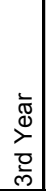 & 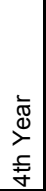 & 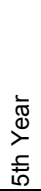 & $\begin{array}{l}\frac{0}{\pi} \\
\frac{\pi}{2} \\
\frac{\pi}{0} \\
0\end{array}$ & 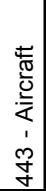 & $\begin{array}{l}\frac{\pi}{\pi} \\
\frac{\pi}{0} \\
\mathbb{0} \\
\mathbb{\pi} \\
\text { की } \\
1 \\
\text { 守 }\end{array}$ & 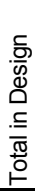 \\
\hline 2002 & & & & & 79 & 102 & 68 & 54 & 59 & 19 & 23 & 26 & 49 \\
\hline 2003 & $93 / 1$ & & $370 / 1$ & & 84 & 84 & 71 & 67 & 64 & 13 & 32 & 26 & 58 \\
\hline 2004 & $108 / 7$ & & $395 / 4$ & & 95 & 86 & 70 & 59 & 85 & 43 & 29 & 29 & 58 \\
\hline 2005 & $77 / 1$ & & $424 / 4$ & & 88 & 104 & 79 & 64 & 89 & 45 & 31 & 38 & 69 \\
\hline 2006 & $129 / 2$ & & $437 / 4$ & & 123 & 91 & 81 & 72 & 70 & 40 & 31 & 27 & 58 \\
\hline 2007 & $204 / 1$ & & $562 / 2$ & & 181 & 137 & 78 & 82 & 84 & 28 & 41 & 28 & 69 \\
\hline 2008 & & & & & & & & & & & 37 & 40 & 77 \\
\hline
\end{tabular}

As graphically depicted by Figure 5, the 2006 and 2007 freshman classes were unexpectedly large; these large freshman classes will enroll in Senior Design in 2009 and 2010. These large classes will put significant strain on the design program - we simply can not take twice as many students on these trips to industry. Consequently, the design faculty are faced with the challenge of significantly scaling up the design program without harming the learning opportunity it provides. As with so many problems of scale, a distributed solution is very attractive. In the Fall of 2009, Cal Poly will introduce a single section of a third Senior Design track following the recipe developed in Aircraft and Spacecraft Design. In 2010, this new track will grow to two sections and will be a full peer of the established tracks. 


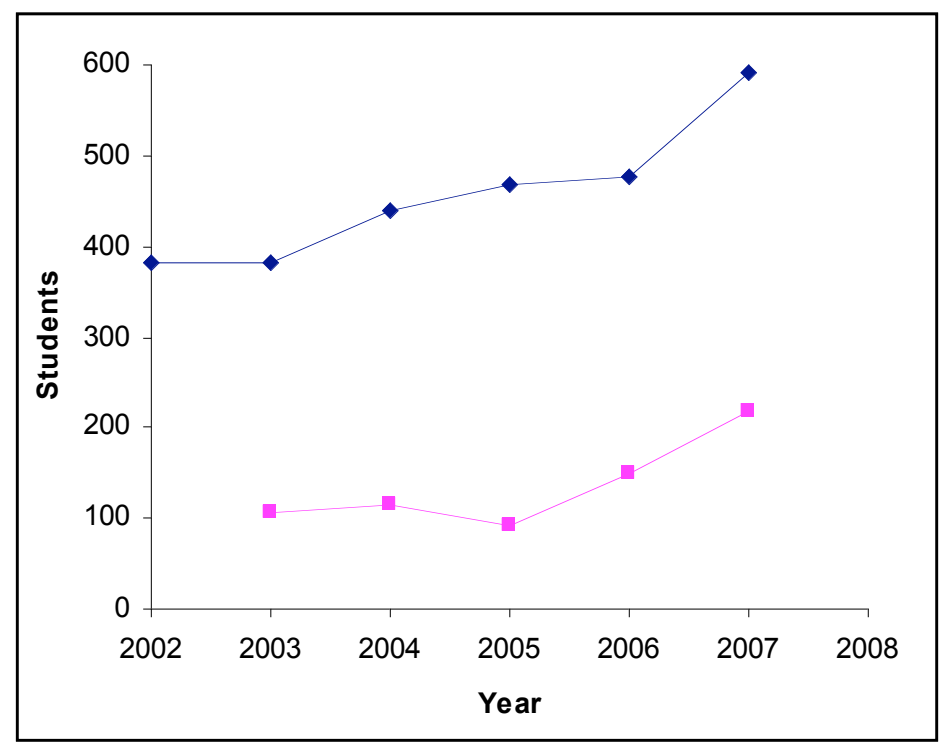

Figure 5. Cal Poly Aerospace enrollment history.

\section{Unmanned Aerial Vehicle Design - A plan for a third track.}

The continued enrollment growth of the Aerospace Engineering department presents a great challenge to the Senior Design program. The current duo of Aircraft and Spacecraft Design courses simply can not accommodate the senior classes projected for 2009 and beyond. In the Fall of 2009, the faculty will introduce a third Senior Design course covering Unmanned Aerial Vehicle (UAV) Design.

The decision to move forward with a UAV design course (as opposed to some other segment of the aerospace industry) was made for a variety of reasons. These included taking a close look at the kinds of jobs our graduates were filling upon graduation. Many of our students were taking jobs with companies like BAE Systems and General Atomics which are focused on UAV's as well as students taking UAV positions with companies like Lockheed, Boeing, and Northrop.

UAVs have finally begun to deliver on decades of promises. Recent successes have resulted in one of the fastest growing areas of aeronautics, defense, and technology in general. As an area of the Aerospace industry clearly set for growth, UAV design was high on the priority list from the start.

Although the faculty wanted to expose our students to an exciting new field, there was also a strong desire to ensure our students were 'compatible' with our existing faculty, curriculum, and the employers who already hire many of our students. Cal Poly's small faculty has little expertise in some of the more exotic sectors of the Aerospace industry; UAV design was seen as a choice within the domain of expertise of the faculty. The prerequisites for the planned UAV track are identical to those for the existing Aircraft Design track; no changes to the curriculum are needed for this new track. We expect the UAV and Aircraft track graduates to be considered for many of the same jobs without hesitation or preference by the companies who hire our students.

Geography played a significant role in choosing UAV Design. Figure 6 is a map of the western United States depicting the UAV companies in the area which are being considered for involvement with the course. Although this design track will necessitate extending our range to San Diego to work with BAE Systems, General Atomics, and Northrop Grumman, we will also be able to work very closely with AeroMech Engineering, a UAV company right in San Luis Obispo. Other opportunities to apply this recipe

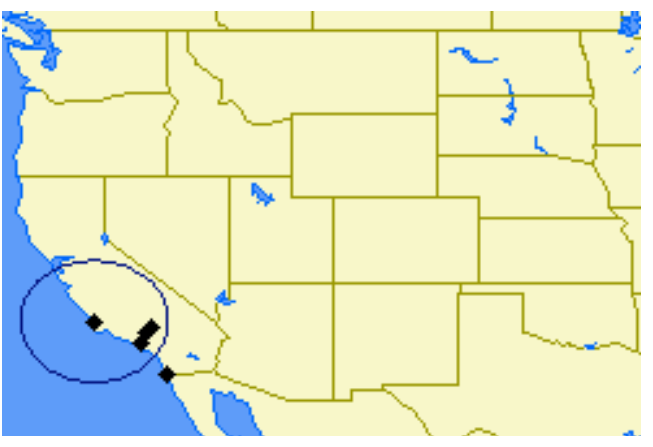

Figure 6. UAV companies being considered to support the new Senior Design track. for design were explored as well; maps resulting from some of these brainstorming sessions were included in Section VIII of this paper. 


\section{Aircraft and Spacecraft - Varied implementations of the recipe.}

In the above sections the fundamental Cal Poly Aerospace capstone design "recipe" has been presented as a highly successful solution to the implementation of an aerospace capstone design course. However, it is important to note, that the "recipe" has been successful even though the aircraft and spacecraft design courses at Cal Poly have significant differences. Some of the basic differences include:

- Readiness Level: The aerospace engineering curriculum at Cal Poly reflects its evolution from an aeronautical engineering program and includes most of the traditional aeronautical engineering topics. As a result, the students in the spacecraft design track are not nearly as well prepared to start designing a system when they begin their design course. As a result the aircraft design students spend the first quarter involved in individual design work while the spacecraft design students spend a large portion of the first quarter learning some of the fundamentals of spacecraft systems.

- RFP source: While the aircraft design course traditionally follows the AIAA design competition RFP the spacecraft design course has an internally developed RFP. This provides consistency in the RFP learning objectives and relates to the readiness level. It is important to guarantees that the students will be exposed to certain spacecraft fundamentals that are not always included in the AIAA spacecraft RFP. The RFP in the spacecraft design course is also less detailed and forces the students to develop some of the systems requirements themselves while the AIAA aircraft RFP typically provides more complete and stricter system requirements.

- Group Size: The internal RFP eliminates some of the team size restrictions imposed by the AIAA and allows the spacecraft students to work as a very large team. The aircraft students are limited by AIAA rules to less than 10 students per team, but typically work in groups of 5-7. As result the aircraft design class involves several teams competing on the same RFP and generating a large number of designs with different solutions.

- Depth of treatment: The spacecraft design problem is largely driven by subsystems such as RF communications, electrical power and thermal control. These subsystems must be analyzed in depth before a successful design can be implemented. As a result the analysis in the spacecraft design course is traditionally more detailed than that in the aircraft design course. This is a good match to the large student groups and is important in the students learning of the spacecraft fundamentals that are not included in their curriculum.

- Design evolution and iterations: The different levels of analysis in the two courses have a significant influence in the way the designs evolve in the two classes as well as the presentations to industry. In the Aircraft design class the conceptual designs are presented to industry from a very early stage and the students evolve their designs through a number of iterations during the year. This makes all the industry presentations similar in content and develops a very mature design at the end of the year. In the spacecraft class the industry presentations represent an evolution $\mathrm{f}$ the design with initial presentations focused on the architectural and overall system trades and the final presentations dealing with more detailed design aspects. This results in a more detailed design but limits the number of iterations.

Given these differences, it is clear that the implementation of the Cal Poly design "recipe" to the new spacecraft sequence is identical that in the aircraft design course. However, the results have been extremely successful. These results should be viewed as a demonstration of the flexibility of the Cal Poly "recipe". It is clear that the basic concepts that have made Cal Poly's aircraft design so successful do apply to other design areas with different challenges and educational objectives. The new UAV track should provide an additional test case and a new and different implementation of the "recipe".

\section{Other Recipe Opportunities}

Although southern California may be the ideal place for a university to work closely with the Aerospace industry, Figure 7 shows where this recipe should be applicable in analogous form across the country. This figure was created to aid in the process for evaluating which new track Cal Poly should undertake; for example Figure $7 \mathrm{~b}$. shows that a launch vehicle design course would be an attractive alternative for Cal Poly to consider. As a consequence of this intent, no attempt was made to map out aerospace industry locations which significantly overlapped with our existing courses. For example, the Boeing facility in St. Louis MO is not depicted on this map.

American Institute of Aeronautics and Astronautics 092407 
A 200mi circle drawn at St. Louis would include three ABET accredited aerospace programs; a 300mi circle would include eight.

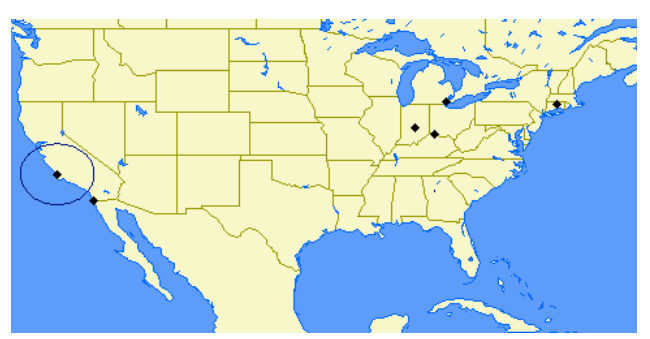

a. Gas Turbine Engine

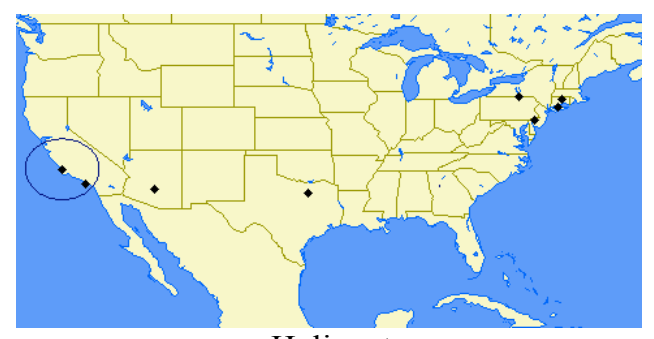

c. Helicopter

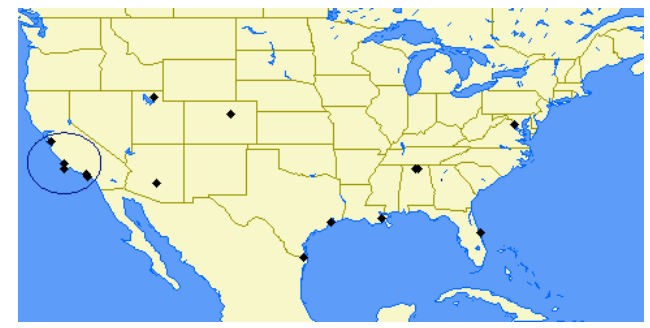

b. Launch Vehicle

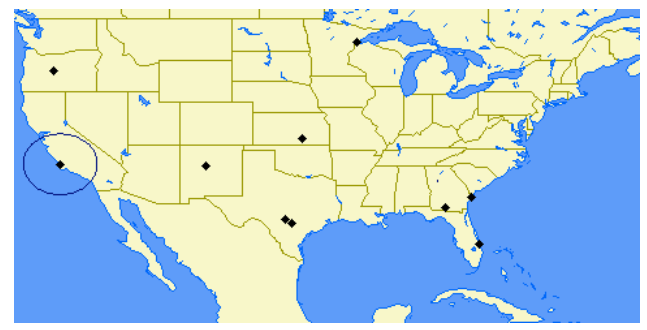

d. General Aviation

Figure 7. Other geographic opportunities for close interaction with industry.

Of course, most universities are not likely to be located near four or five aerospace institutions. However, senior design students can gain a great deal from a single critical review. A year-long senior design program located within 200miles of a single aerospace institution could implement a program with two critical reviews. This may entail a first review, on site, at the end of the first semester combined with a second review, on campus, at the end of the academic year.

Many sectors of interest to the Aerospace community have been left off of these maps. Tactical missiles, strategic missiles and missile defense, manned spacecraft, deep space probes, extraterrestrial land vehicles, rocket and space propulsion, hypersonic cruise propulsion and vehicles, ship and submarine design, and wind energy to name a few. In addition, the Cal Poly recipe should be applicable to design areas outside aerospace as appropriate.

\section{Faculty Profiles}

\section{A. Dr. Rob McDonald}

Rob McDonald obtained his Ph.D. from the Aerospace Systems Design Lab (ASDL) at Georgia Tech in 2006. His primary research interests include Complex Systems Design, Multidisciplinary Design Analysis and Optimization, Aircraft Design, Aircraft Performance, Unmanned Aerial Vehicles, and Advanced Aircraft Concepts.

\section{B. Dr. Jordi Puig-Suari}

Jordi Puig-Suari obtained his Ph.D. from Purdue in 1993. His primary research interests are space systems and spacecraft design. While at Cal Poly he has been involved in the creation of the CubeSat program including the development and launch of a number of spacecraft. In collaboration with Lockheed Martin he has also lead the developed a graduate space systems engineering masters program.

\section{Mr. Dave Esposto}

David Esposto graduated from Cal Poly in 1973 with a BS in Aeronautical Engineering. He is a retired Engineer and spent his career at Boeing Satellite Systems (formerly Hughes Space and Communications) in El Segundo, California. He started as a structural engineer and moved up to the position of Chief engineer in a number of spacecraft programs including Direct TV 10 and 11. He has also received a number of patents and awards including the Hughes Lawrence A. Hyland Patent Award and the appointment as Associate Technical Fellow. During his years in industry he maintained his ties to Cal Poly and was a key industry contact for the spacecraft design course. 


\section{Mr. Bruce Wright}

Bruce Wright obtained his BS in Aerospace Engineering from Virginia Tech in 1962. He is a retired Aeronautical Engineer, Program Manager, and Chief Operations Officer with 40 years of experience in leading the development of a wide variety of aircraft: commercial transports, fighters, reconnaissance, unmanned, and hybrid. He worked at NASA Langley from 1962-1965 and then Lockheed Martin from 1965-1999, most of that time with the Skunk Works. He served as program Manager of F-22 from 1983-1985 and program Manager for Dark Star 1993-1995; he holds the design patent for the Dark Star UAV.

\section{Acknowledgments}

The Great Circle Mapper Copyright (C) 1996-2008, Karl L. Swartz http://gc.kls2.com/ was used to generate the maps for this paper.

\section{References}

${ }^{1}$ Cummings, R.M., Hall, D.W., and Sandlin, D.R., "Decades of Innovation in Aircraft Design Education," 47 ${ }^{\text {th }}$ AIAA Aerospace Sciences Meeting, Orlando FL, AIAA Paper 2009-1603, Jan. 2009.

${ }^{2}$ Hall, D.W., and Cummings, R.M., "The Happy Accidents of Teaching Aircraft Design," AIAA 45th Aerospace Sciences Meeting, Reno NV, AIAA Paper 2007-0302, Jan. 2007.

${ }^{3}$ Cummings, R.M. and Hall, D., "Aircraft Design for Second-Year Undergraduate Students," International Journal of Engineering Education, Vol. 21, No. 2, 2005, pp. 341-349.

${ }^{4}$ Cummings, D.B. and Hall, D.W., "Exploiting the Creative Process for Innovative Air Vehicle Design," AIAA 42 Aerospace Sciences Meeting, Reno NV, AIAA Paper 2004-0417, Jan. 2004.

${ }^{5}$ Cummings, R.M., "From Biplanes to Reusable Launch Vehicles: 75 Years of Aircraft Design at Cal Poly," AIAA 41 ${ }^{\text {st }}$ Aerospace Sciences Meeting, Reno NV, AIAA Paper 2003-0233, Jan. 2003.

${ }^{6}$ McMasters, J.M. and Cummings, R.M., “Aircraft Design-Past, Present, and Future,” Journal of Aircraft, Vol. 39, No. 1, 2002, pp. 10-17.

${ }^{7}$ Cummings, R.M. and Freeman, H.J., "Integrating Multidisciplinary Design in an Undergraduate Curriculum," SAE Transactions, Vol. 106, No.1, 1997, pp. 1665-1670.

${ }^{8}$ Soban, D.S., "Aircraft Design Education-A Student's Perspective," AIAA Aircraft Design, Systems, and Operations Meeting, Monterey CA, AIAA Paper 93-3993, Aug. 1993.

'Sandlin, D.R. and van't Riet, R., "The Cal Poly Aircraft Design Program,” AIAA Aerospace Design Conference, Irvine CA, AIAA Paper 93-1111, Feb. 1993. 